\title{
Nanoparticulat Printex 90 and Titanium Dioxide Stimulate Catecholamine Production in Ciliated Protozoan, Tetrahymena thermophila
}

\section{Asad Ud-Daula ${ }^{1,3 *}$ and Karl-Werner Schramm ${ }^{2,3}$}

${ }^{1}$ Helmholtz Zentrum München - German Research Center for Environmental Health (GmbH), Molecular EXposomics (MEX), Ingolstädter Landstr.1, Neuherberg, Germany ${ }^{2}$ TUM, Wissenschaftszentrum Weihenstephan für Ernährung, Landnutzung und Umwelt, Department für Biowissenschaften, Weihenstephaner Steig 23, Freising, Germany ${ }^{3}$ Department of Applied Nutrition and Food Technology, Faculty of Applied Science and Technology, Islamic University, Kushtia, Bangladesh

\begin{abstract}
The aim of this study was to find the effect of printex 90 and titanium dioxide nanoparticle on catecholamine homeostasis in Tetrahymena thermophila. These two nanoparticles were exposed for 20 hours and 40 hours respectively. Tetrahymena cell produce catecholamine which was extracted by solid phase extraction and then analyzed by HPLCECD. Nanoparticles cause the stimulation of catecholamine production to the Tetrahymena. Noradrenaline and dopamine were predominantly synthesized in the cell with exposure of nanoparticles. Printex 90 induces strong stimulation of cell for catecholamine synthesis as compared to titanium dioxide. The production level of catecholamine increases with higher doses of nanoparticles with few exceptions. Nevertheless, this study clearly claims that nanoparticle increases catecholamine synthesis and causes subsequent toxicity.
\end{abstract}

Keywords: Nanoparticle; Printex 90; Titanium dioxide; Catecholamine

\section{Introduction}

Nanoparticles and nanomaterials are being rapidly produced in large quantities throughout the world due to their attractive usefulness. It has special properties such as small size (1-100 nm), high surface area and structure. Carbon black, printex 90 (CB) is a single walled carbon nanotube (SWCNT). It is extensively used in jet coloring of plastics and powder coatings due to good dispersibility and higher structure. On the other hand, titanium dioxide $\left(\mathrm{TiO}_{2}\right)$ nanoparticle plays a special role in photocatalyst and catalytic support as well as a white pigment in the production of paints, paper, plastics, sunscreens and cosmetics [1,2]. Therefore, considering their wide range of applications, the impact of nanomaterials on human health and the environment makes it great interest. In the recent years, the increasing evidence of the adverse effects of nanoparticles, such as increase in respiratory and cardiovascular mortality, morbidity and worsening of asthma [3-5]. Many types of commercial nanoparticles, such as silica, $\mathrm{TiO}_{2}$, silver, chrysotile asbestos, carbon nanotubes, as well as some magnetic particles, have been investigated for their bio-safety, and these nanoparticles exhibited various levels of cytotoxicity in different cell lines [4,6]. However, the recent time it is also reported that upconversion nanoparticles composites are useful to control multifunctional drug delivery and reduce drawbacks of drug [7-9]. The mice treated with platinum(IV) pro-drug-conjugated nanoparticles under near-infrared (NIR) irradiation demonstrated better inhibition of tumor growth than that of the under direct UV irradiation [7]. A chemotherapy drug, doxorubicin, is loaded into the nanocomposite, forming an upconversion nanoparticles (UCNPs) together with iron oxide nanoparticles (IONPs) which enables novel imaging-guided and magnetic targeted drug delivery [8]. Subsequently, the combination of upconversion nanoparticles with the cisplatin (IV) prodrug will reduce not only the drawbacks of cisplatin but also give insight into its in vitro/in vivo imaging [9]. Multi-walled carbon nanotube frequently penetrates and sustained into alveolar macrophages, the alveolar wall, and visceral pleura of mice [10]. In addition, nanoparticle carbon black induces neurological effect and modulates the extracellular amino acid neurotransmitter levels and proinflammatory cytokine IL-1 $\beta$ mRNA expressions synergistically with lipoteichoic acid in the mice olfactory bulb [11]. Printex 90 induces lung granulomas after intratracheal administration $[12,13]$. Its exposure also causes potential dermal and cellular toxicity [14]. On the other hand, $\mathrm{TiO}_{2}$ nanoparticle causes inflammation, fibrosis, pulmonary damage, and even DNA damage [15]. The maternal exposure of $\mathrm{TiO}_{2}$ nanoparticles to mice affects the expression of genes in early stage that is related to the development and function of the central nervous system [16]. Furthermore, the nasal instillation of $\mathrm{TiO}_{2}$ nanoparticles produce oxidative stress in whole brain of exposed mice such as lipid peroxidation, protein oxidation and increased activities of catalase, as well as the excessive release of glutamic acid and nitric oxide and cause potential lesion in central nervous system of brain [17]. As far we know, many investigation of nanoparticle was conducted on vertebrates and mammalian cells. However, this study utilizes single cell ciliate protozoan, Tetrahymena thermophila as a model organism to test nanoparticles. In spite of this, few studies have been shown that nanoparticle causes toxicity to Tetrahymena. $\mathrm{nCuO}$ significantly decreases the proportion of unsaturated fatty acids (UFA) while it increases the relative amount of two saturated fatty acids by lowering membrane fluidity and inhibition of de-novo synthesis of fatty acid desaturases in Tetrahymena [18]. In addition, $\mathrm{Ag}, \mathrm{CuO}$ and $\mathrm{ZnO}$ nanoparticle induces toxicity and decreases growth of Tetrahymena [19-21]. The aquatic organism, Tetrahymena synthesizes dopamine, noradrenaline and adrenaline at significant level although this organism does not contain adrenal medulla or nervous system [22]. As well, literature has recently been revealed that $\mathrm{TiO}_{2}$ nanoparticle causes cytotoxicity to the Tetrahymena [23]. However, our previous literature showed that the prenatal exposure of $\mathrm{TiO}_{2}$ causes the increase of dopamine and its metaboloite in the different region of the brain in mice [24]. Therefore, the aim of the study was to explore

*Corresponding author: Asad Ud-Daula, Helmholtz Zentrum München - German Research Center for Environmental Health $(\mathrm{GmbH})$, Molecular EXposomics (MEX), Ingolstädter Landstr.1, Neuherberg, Germany Tel: +88 071 74910-21 2306; Fax: +88071 74950: E-mail: asad.uddaula@googlemail.com

Received: August 20, 2015; Accepted: October 28, 2015; Published October 30, 2015

Citation: Ud-Daula A, Schramm K (2015) Nanoparticulat Printex 90 and Titanium Dioxide Stimulate Catecholamine Production in Ciliated Protozoan, Tetrahymena thermophila. Biochem Anal Biochem 4: 212. doi:10.4172/2161-1009.1000212

Copyright: (c) 2015 Ud-Daula A et al. This is an open-access article distributed under the terms of the Creative Commons Attribution License, which permits unrestricted use, distribution, and reproduction in any medium, provided the original author and source are credited. 
Citation: Ud-Daula A, Schramm K (2015) Nanoparticulat Printex 90 and Titanium Dioxide Stimulate Catecholamine Production in Ciliated Protozoan, Tetrahymena thermophila. Biochem Anal Biochem 4: 212. doi:10.4172/2161-1009.1000212

Page 2 of 5

the effect of printex 90 and $\mathrm{TiO}_{2}$ nanoparticle on the catecholamine homeostasis in Tetrahymena thermophila as an 'animal free testing organism' in 96-well plates.

\section{Materials and Methods}

Two different nanoparticle (NP) such as printex 90 and $\mathrm{TiO}_{2}$ were used in this study. Printex 90 was purchased from Evonik Degussa GmbH, Rellinghauser Straße 1-11, D-45128 Essen, Germany. The manufacturer reported that it is carbon black nanoparticle (CBNPs) with an average size of $14 \mathrm{~nm}$. The specific surface area was determined to be $295-338 \mathrm{~m}^{2} / \mathrm{gm}$ corresponding to a theoretical average spherical particle size of 8.1-9.5 $\mathrm{nm}$. It contains organic impurity less than $1 \%$. The total carbon content was measured greater than $99 \mathrm{wt} \%$ with 0.82 nitrogen wt $\%$ and 0.01 hydrogen wt $\%$. The literature also described that printex 90 particles in suspensions for exposure showed the average zeta-size was $140 \mathrm{~nm}$ and the hydrodynamic number size distribution had the major mode at 50-60 $\mathrm{nm}$ [25]. On the other hand, $\mathrm{TiO}_{2}$ was purchased from Sigma- Aldrich, Taufkirchen, Germany. The manufacturer describes that it is a titanium (IV) oxide, anatase, $99.7 \%$ trace metals basis. Its average size is $25 \mathrm{~nm}$. Its surface area, bulk density and density at $25^{\circ} \mathrm{C}$ were $45-55 \mathrm{~m}^{2} / \mathrm{g}, 0.04-0.06 \mathrm{~g} / \mathrm{mL}$ and $3.9 \mathrm{~g} / \mathrm{mL}$ respectively. The stock suspension of printex 90 and $\mathrm{TiO}_{2}$ nanoparticles were prepared in proteose peptone yeast (PPY) extract cell culture medium separately and stabilized by ultra-sonication (Sonorex RK 510S, Bandelin, Berlin, Germany). Nanoparticles suspensions were test to unicellular ciliate protozoan cell, Tetrahymena thermophila SB210 for catecholamine homeostasis. The growth maintenance of this cell was described in the literature [23]. Tetrahymena cell was acclimatized in fresh PPY-medium by twice successive reseedings for producing exponential cell. The sterile stock suspension of nanoparticle was prepared in PPY-medium. It was ultra-sonicated for one hour prior to experiment for stabilization. $200 \mu \mathrm{l}$ printex 90 nanoparticle suspension of different concentration and $50 \mu \mathrm{l}$ exponential cells aliquot were added to different well of 96-well plates. The final volume of liquid in each well in 96-well plates is reached to $250 \mu \mathrm{l}$. As well, the initial Tetrahymena cell concentration in the 96-well plate was carefully maintained to $1 \times 10^{4}$ cell $/ \mathrm{mL}$ by adding adjusted $50 \mu \mathrm{l}$ cell aliquots. Cell concentration was measured by Neubauer cell counter (Brand Wertheim, Germany). Due to the addition of different concentration of printex 90 nanoparticles in the 96 -well plate were produced the final exposure concentrations of nanoparticle to $2.67,4,6,9,13.5,15.8$, $23.70,35.56,53.33,80,120,180 \mathrm{mg} / \mathrm{L}$ respectively. In addition, $\mathrm{TiO}_{2}$ nanoparticle was also tested as similar as printex 90 . However, the final exposure concentrations of $\mathrm{TiO}_{2}$ nanoparticle were calculated to 8 , $16,20,24,32,40,80,100,120,160$ and $200 \mathrm{mg} / \mathrm{L}$ respectively. Now, the prepared 96 -well plates were placed into horizontal shaker at 40 $\mathrm{rpm}$ in dark for incubation and cultivation of cell at $32^{\circ} \mathrm{C}$ for 20 hours and 40 hours respectively. This slow shaking of 96 -well plate aided nanoparticles to keep suspension in the PPY-medium. Nevertheless, nanoparticle tends to accumulate in the well plates due to the presence of complex PPY medium with the association of many ions. It is also recently reported upon a microscopic study that this accumulation of nanoparticle increases significantly when Tetrahymena species was cultivated in the PPY medium [23]. Tetrahymena cell internalize all free nanoparticles and finally exocytose them as larger aggregates into the culture medium, and this process continues until free small and visible nanoparticles are present the PPY-medium. However, the molecular mechanism of this particle internalization into Tetrahymena was not clear. In addition, the size distribution and zeta-potential of these two nanoparticles were not measured in PPY-medium in this study; size distribution of nanoparticles in PPY-medium was shown in our previous literature [23].
$200 \mu \mathrm{L}$ experimental aliquots from 96-well plates was aspirated and transfer into solid phase extraction (SPE) cartridge after 20 hours and 40 hours incubation respectively accordingly with $50 \mu \mathrm{l}(=500 \mathrm{pg})$ internal standard (IS) solution (3,4 dihydroxybenzylamine, DHBA). Sample clean-up for catecholamine was carried out according to the manufacturer guide lines (ClinRep ${ }^{\star}$ HPLC Complete kit, Recipe, Germany). Catecholamine concentration was measured by HPLC-ECD as per description of literature [22]. The analytical precision, accuracy and the lower limits of determination were determined from biological control materials (ClinRep ${ }^{\oplus}$ HPLC Complete kit, Recipe, Germany). The recovery rate for the catecholamine in the control materials (blood plasma) was found above $80 \%$. The quantitative data of the catecholamine was estimated using peak area of chromatogram as per standard formula of ClinRep HPLC (Recipe, Germany).

The data from the all groups of nanoparticle dose were pooled and analyzed statistically using Two-tailed "Student t-distribution" test in order to compare with control to find significance of differences, where $\mathrm{p}$ value $<0.05$ was considered for significant result. Data of the control group $(n=3)$ was compared to the data of each treatment $(n=3)$ group for the catecholamine parameter of dopamine, adrenaline and noradrenaline separately.

\section{Results and discussion}

Nanoparticles were exposed to Tetrahymena to study catecholamine homoeostasis in 96-well plate. Three catecholamine compounds, namely noradrenaline (NA), adrenaline (A), and dopamine (DA), are known to be significantly synthesized in Tetrahymena and are quantitatively determined by HPLC-ECD using the ClinRep ${ }^{\circ}$ HPLC complete kit [22]. This technique is very useful for the analysis of catecholamine at low concentration in several physiological fluids, eg. plasma and urine da 2006) [26]. A standard solution of catecholamine (ClinRep ${ }^{\star}$ ) was used to prepare a standard chromatogram for the analysis of catecholamine through isocratic separation as illustrated in Figure 1a.

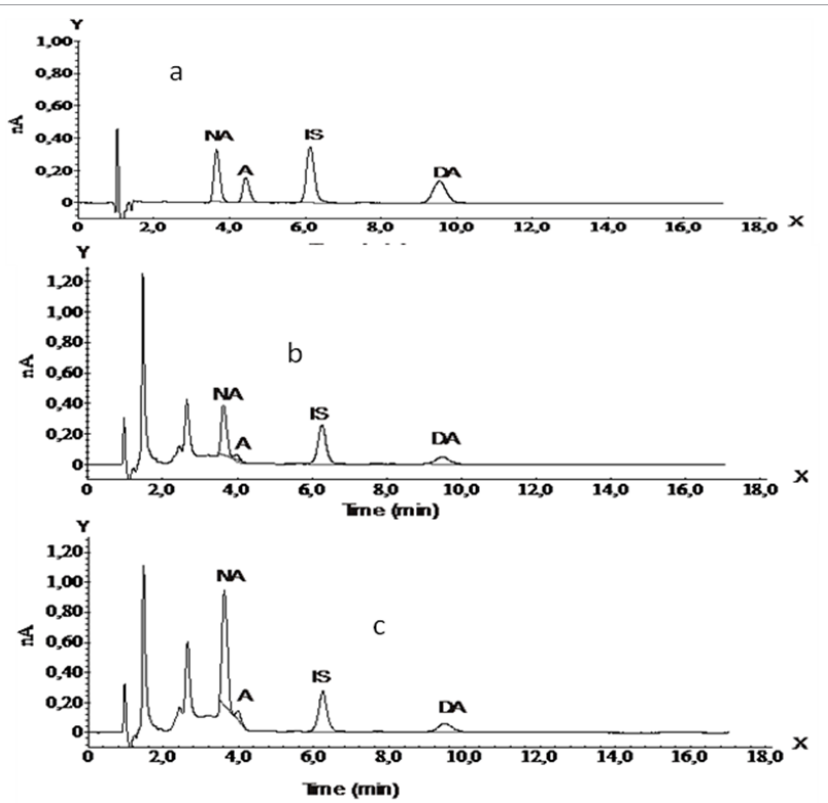

Figure 1: Chromatogram of catecholamine. (a) Standard chromatogram. Where, noradrenaline (NA), adrenaline (A), internal standard (IS) and dopamine (DA) respectively. (b) Catecholamine produced from Tetrahymena cell after 40 hour without exposure of nanoparticle. (c) Catecholamine produced from Tetrahymena with the exposure of printex 90 after 40 hours where nanoparticle concentration was $80 \mathrm{mg} / \mathrm{L}$. 
Citation: Ud-Daula A, Schramm K (2015) Nanoparticulat Printex 90 and Titanium Dioxide Stimulate Catecholamine Production in Ciliated Protozoan, Tetrahymena thermophila. Biochem Anal Biochem 4: 212. doi:10.4172/2161-1009.1000212

Page 3 of 5

\begin{tabular}{|c|c|c|c|c|c|c|c|c|c|c|c|c|}
\hline \multirow[b]{3}{*}{$\mathrm{mg} / \mathrm{L}$} & \multicolumn{6}{|c|}{20 hour exposure of Printex 90} & \multicolumn{6}{|c|}{40 hour exposure of Printex 90} \\
\hline & \multicolumn{2}{|c|}{ Noradrenaline } & \multicolumn{2}{|c|}{ Adrenaline } & \multicolumn{2}{|c|}{ Dopamine } & \multicolumn{2}{|c|}{ Noradrenaline } & \multicolumn{2}{|c|}{ Adrenaline } & \multicolumn{2}{|c|}{ Dopamine } \\
\hline & $\mathrm{nmol}$ & SD & $\mathrm{nmol}$ & SD & $\mathrm{nmol}$ & SD & $\mathrm{nmol}$ & SD & $\mathrm{nmol}$ & SD & $\mathrm{nmol}$ & SD \\
\hline Control & 49.8 & 5.64 & 1.13 & 0.43 & 12.17 & 2.90 & 65.47 & 3.92 & 2.82 & 1.02 & 21.37 & 3.29 \\
\hline 2.67 & 60.82 & 6.08 & 0.95 & 0.25 & 13.14 & 2.19 & 68.09 & 1.12 & 2.31 & 0.06 & 18.71 & 0.35 \\
\hline 4 & $82.89^{*}$ & 3.34 & 1.37 & 0.25 & $25.17^{*}$ & 1.81 & $79.99^{*}$ & 4.41 & 2.48 & 0.49 & 21.54 & 3.88 \\
\hline 6 & 64.07 & 7.21 & 1.93 & 1.02 & 18.47 & 3.52 & 70.72 & 0.60 & 2.53 & 0.08 & 18.31 & 0.18 \\
\hline 9 & 63.95 & 2.68 & 2.16 & 0.11 & 17.29 & 0.81 & $78.97^{\star}$ & 5.42 & 2.55 & 0.51 & 21.05 & 1.79 \\
\hline 13.5 & $64.16^{*}$ & 3.95 & 1.72 & 0.11 & 16.98 & 1.24 & $94.81^{*}$ & 5.15 & 2.47 & 0.18 & 27.37 & 1.67 \\
\hline 15.8 & 59.49 & 6.16 & 0.97 & 0.21 & 13.36 & 2.42 & $92.73^{*}$ & 5.59 & 3.70 & 0.18 & $31.25^{*}$ & 3.53 \\
\hline 23.70 & $65.83^{*}$ & 5.15 & 0.73 & 0.14 & 14.45 & 1.34 & $75.75^{\star}$ & 1.12 & 1.64 & 0.10 & 26.17 & 0.23 \\
\hline 35.56 & 60.04 & 1.52 & 1.09 & 0.02 & 12.52 & 0.90 & 74.19 & 2.92 & 2.74 & 0.07 & 21.55 & 1.18 \\
\hline 53.33 & $68.17^{*}$ & 3.43 & 1.91 & 0.16 & 16.31 & 0.91 & $105.8^{*}$ & 2.14 & 3.98 & 0.19 & 26.92 & 1.32 \\
\hline 80 & $94.86^{*}$ & 4.10 & $2.6^{*}$ & 0.14 & $23.92^{*}$ & 1.20 & $106.6^{*}$ & 3.99 & 4.09 & 0.21 & $30.07^{*}$ & 1.77 \\
\hline 120 & $96.34^{*}$ & 2.24 & $2.9^{*}$ & 0.13 & $28.56^{*}$ & 0.86 & $95.41^{*}$ & 2.77 & 3.21 & 1.06 & 26.38 & 5.09 \\
\hline 180 & $101.85^{*}$ & 3.87 & 1.65 & 0.18 & $28.59^{*}$ & 1.41 & 74.35 & 5.35 & 2.51 & 0.34 & 26.09 & 3.13 \\
\hline
\end{tabular}

Table 1: Effect of printex 90 nanoparticle on catecholamine homeostasis in Tetrahymena thermophila after 20 hour and 40 hour exposure. ( $\left.{ }^{*}\right)$ indicates a significant difference of analytes as compared to the control.

Then the peak area of the desired compounds in the chromatogram of sample exposed by nanoparticles were identified and detected by comparison with peak area of standard chromatogram using retention time. However, in biological samples the retention time of analytes is slightly shifted due to the presence of some ions and trace metabolites but it does not affect the performance of catecholamine estimation. A chromatogram for normal synthesis of catecholamine in Tetrahymena was used to compare with the chromatogram of catecholamine exposed by nanoparticles as shown in Figure 1b. The exposed nanoparticles were internalized into the Tetrahymena cell and later exocytosed from the cell as bigger aggregates. However, during this discharge process of nanoparticles by the Tetrahymena cell turns to stimulate synthesis of noradrenaline, adrenaline and dopamine. This extra production of catecholamine from Tetrahymena cells with the exposure of printex 90 at $80 \mathrm{mg} / \mathrm{L}$ concentration after 40 hours was shown in Figure 1c. The comparison between Figure $1 \mathrm{~b}$ and 1c clearly exhibited that printex 90 induces Tetrahymena cell for the additional synthesis of catecholamine. Similarly, all the exposure concentration of printex 90, as described in the methodology section, stimulated Tetrahymena for additional synthesis of noradrenaline, adrenaline and dopamine. Among these three compounds noradrenaline was most profoundly synthesized in the cell as compared to control. Most of the doses of printex 90 were significantly produced noradrenaline after 20 hours as presented in Table 1. However, the noradrenaline production was found to be very high and is not consistent for the printex 90 at 4, 80,120 and $180 \mathrm{mg} / \mathrm{L}$ as compared to the other remaining doses. We can't explain this irregular higher response of noradrenaline in response to printed 90; it may be caused due to the uneven sensitivity of electrode in detector of HPLCECD. Similarly, adrenaline and dopamine were also progressively synthesized in the cell with the exposure of printex 90. It is also showed that the level of adrenaline production was very low as compared to the noradrenaline and dopamine. Only two dose of printex 90 at 80 and $120 \mathrm{mg} / \mathrm{L}$ were caused significant increase of adrenaline synthesis after 20 hours incubation. In addition, printex 90 was caused significant production of dopamine at 4, 80,120 and $180 \mathrm{mg} / \mathrm{L}$ as presented in Table 1. Furthermore, printex 90 was also demonstrated the same increasing patterns of noradrenaline, adrenaline and dopamine synthesis after 40 hours of exposure as presented in Table 1. The production of these three compounds was significantly increased with almost all the higher doses of printex 90 with few exceptions. Besides this, the level of these three compounds were higher for 40 hours exposure of printex 90 than after 20 hours, which can be explained due to the continuous production, degradation and net accumulation of catecholamine by new reproducing Tetrahymena cell and longer incubation time (40 hours). Printex 90 at 13.5, 15.8, 53.33, 80 and $120 \mathrm{mg} / \mathrm{L}$ were demonstrated significantly higher level of noradrenaline synthesis as compared to other concentrations. Nevertheless, the overall pattern of noradrenaline synthesis tends to increase with increasing amounts of printex 90 . Additionally, the pattern of dopamine synthesis was also increased as similar to noradrenaline. Here, significant increases of dopamine synthesis were shown only for doses at 15.8 and $80 \mathrm{mg} / \mathrm{L}$. However, in this experiment adrenaline was found to be non-significant production.

In addition, the exposure of $\mathrm{TiO}_{2}$ nanoparticle for 20 hours induces chemical signals in the cell and this study found to be irregular production of noradrenaline and dopamine. Most of the exposure dose of $\mathrm{TiO}_{2}$ nanoparticle was induced significantly higher production of noradrenaline and dopamine as compared to control after 20 hours as presented in Table 2. Adrenaline synthesis was also increased. However, surprisingly dopamine concentration was much higher as compared to the previous analysis for unknown reasons. $\mathrm{TiO}_{2}$ nanoparticle at dose of $8,16,20$ and $24 \mathrm{mg} / \mathrm{L}$ were stimulated dopamine synthesis and its higher concentration causes slight depletion of dopamine. Notwithstanding, this study was explored that $\mathrm{TiO}_{2}$ nanoparticle causes the additional production of dopamine as compared to control. On the other hand, when this particle was exposed for 40 hours, causes slight additional synthesis of noradrenaline and dopamine for all the applied doses, with the exception that few concentrations of particles decreased the production of noradrenaline and dopamine as shown in Table 2. In addition, 40 hours incubation of this particle apparently did not show any effect on adrenaline.

Catecholamine compounds are also potentially produced in the Tetrahymena although this cell does not possess nervous system [22]. In this study, the exposure of printex 90 and $\mathrm{TiO}_{2}$ exhibited a remarkable result on catecholamine homeostasis in Tetrahymena for both incubation times of 20 hours and 40 hours. It stimulates cells and significantly produced noradrenaline and dopamine for most of the doses, and the production level of these compounds increases with increasing concentrations of nanoparticle with few exceptions. However, the measured concentration of noradrenaline and dopamine for some higher concentrations of printex 90 were found slightly lower as compared to the lower concentrations of printex 90 for both the incubation times. A similar effect was also found for the exposure of $\mathrm{TiO}_{2}$. This fact may be caused by the cytotoxicity of printex 90 and $\mathrm{TiO}_{2}$ 
Citation: Ud-Daula A, Schramm K (2015) Nanoparticulat Printex 90 and Titanium Dioxide Stimulate Catecholamine Production in Ciliated Protozoan, Tetrahymena thermophila. Biochem Anal Biochem 4: 212. doi:10.4172/2161-1009.1000212

Page 4 of 5

\begin{tabular}{|c|c|c|c|c|c|c|c|c|c|c|c|c|}
\hline \multirow[b]{3}{*}{$\mathrm{mg} / \mathrm{L}$} & \multicolumn{6}{|c|}{20 hour exposure of $\mathrm{TiO}_{2}$} & \multicolumn{6}{|c|}{40 hour exposure of $\mathrm{TiO}_{2}$} \\
\hline & \multicolumn{2}{|c|}{ Noradrenaline } & \multicolumn{2}{|c|}{ Adrenaline } & \multicolumn{2}{|c|}{ Dopamine } & \multicolumn{2}{|c|}{ Noradrenaline } & \multicolumn{2}{|c|}{ Adrenaline } & \multicolumn{2}{|c|}{ Dopamine } \\
\hline & $\mathrm{nmol}$ & SD & $\mathrm{nmol}$ & SD & $\mathrm{nmol}$ & SD & $\mathrm{nmol}$ & SD & $\mathrm{nmol}$ & SD & $\mathrm{nmol}$ & SD \\
\hline Control & 50.25 & 3.54 & 5.10 & 1.04 & 32.58 & 2.87 & 55.40 & 2.19 & 5.13 & 1.66 & 27.03 & 0.84 \\
\hline 8 & $63.12^{*}$ & 2.76 & 5.94 & 0.77 & 39.82 & 0.91 & 50.30 & 2.79 & 5.29 & 1.89 & 23.83 & 6.48 \\
\hline 16 & $66.18^{*}$ & 0.63 & 8.76 & 2.10 & $47.66^{*}$ & 3.79 & $44.42^{*}$ & 1.18 & 3.88 & 0.42 & 21.94 & 4.26 \\
\hline 20 & 56.26 & 6.31 & 8.01 & 2.57 & 46.35 & 5.70 & $62.75^{*}$ & 1.71 & 4.64 & 2.89 & $33.29^{*}$ & 1.12 \\
\hline 24 & $74.15^{*}$ & 4.36 & 9.51 & 2.31 & $54.84^{*}$ & 4.24 & 60.01 & 2.01 & 4.20 & 3.43 & 20.17 & 3.88 \\
\hline 32 & 71.09* & 1.20 & $10.54^{*}$ & 0.87 & $50.92^{*}$ & 2.95 & 56.87 & 2.38 & 3.38 & 2.64 & 30.23 & 3.14 \\
\hline 40 & $85.18^{*}$ & 2.48 & $11.69^{*}$ & 0.81 & $48.31^{*}$ & 4.41 & 56.97 & 2.99 & 4.69 & 0.79 & $36.89^{*}$ & 2.29 \\
\hline 80 & $70.29^{*}$ & 4.82 & 7.01 & 0.57 & $47.07^{*}$ & 1.16 & 51.28 & 0.63 & 3.44 & 0.45 & 28.01 & 4.08 \\
\hline 100 & $65.20^{*}$ & 1.54 & 3.84 & 0.23 & 33.62 & 2.15 & 42.46 & 6.25 & 5.68 & 1.58 & $20.11^{*}$ & 2.01 \\
\hline 120 & 57.67 & 2.18 & 4.34 & 0.41 & $41.32^{*}$ & 0.87 & 49.71 & 7.35 & 5.51 & 3.17 & 23.05 & 3.58 \\
\hline 160 & $71.03^{*}$ & 3.95 & 4.50 & 2.36 & 40.54 & 3.49 & 52.26 & 2.27 & 6.22 & 1.39 & 28.72 & 3.51 \\
\hline 200 & $64.10^{*}$ & 0.91 & 5.76 & 1.25 & $49.48^{*}$ & 1.35 & $40.99^{*}$ & 1.33 & 3.22 & 0.26 & $23.50^{*}$ & 0.85 \\
\hline
\end{tabular}

Table 2: Effect of $\mathrm{TiO}_{2}$ nanoparticle on catecholamine homeostasis in Tetrahymena thermophila after 20 hour and 40 hour exposure. $\left({ }^{*}\right)$ indicates a significant difference of analytes as compared to the control.

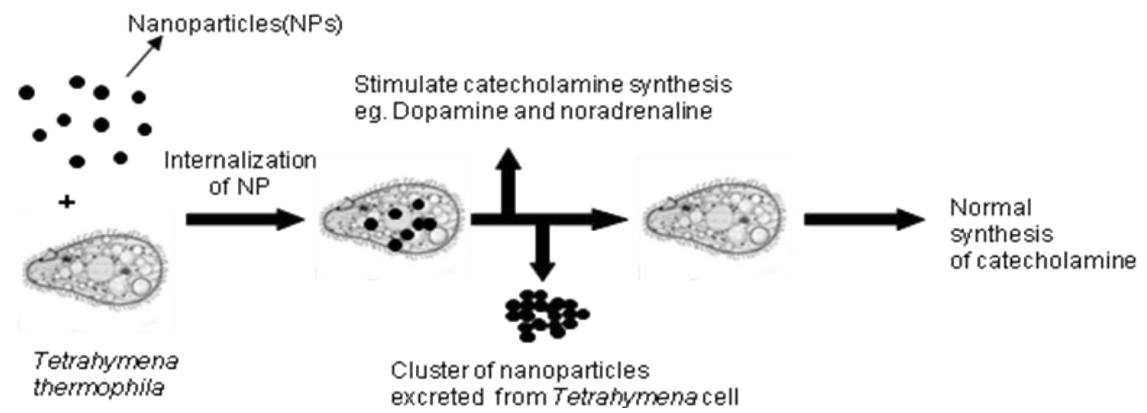

Figure 2: Stimulation of catecholamine synthesis in the Tetrahymena thermophila cell with the exposure of nanoparticles.

at higher concentrations, due to the depletion of cell number. This unconquered effect of nanoparticles was explained in the literature [23]. The authors were reported that higher concentration of $\mathrm{TiO}_{2}$ particle causes cytotoxicity to cells. As a result; due to the presence of lower number of cells were collectively produced smaller amounts of noradrenaline, adrenaline and dopamine.

In a brief, this study showed that nanoparticle induces chemical signal which is associated to stimulate catecholamine production in the aquatic model organism Tetrahymena as illustrated in Figure 2. Tetrahymena was more responsive to printex 90 than $\mathrm{TiO}_{2}$ for elevating catecholamine synthesis, although, Tetrahymena cell does not contain nervous system. Therefore, this study concluded that nanoparticles can be considered as new chemical factor to stimulate catecholamine production in Tetrahymena. Furthermore, this study recommends catecholamine as an important parameter for studying the neurotoxicity of nanoparticle in different model experimental mammalians and other cell lines which potentially synthesize catecholamine. This can also find the bridge of studying the mechanism of toxicity associated with nanoparticles and also in addition to explore the target enzymes of nanoparticles.

\section{Acknowledgement}

This research was supported and funded by Helmholtz Zentrum München German Research Center for Environmental Health $(\mathrm{GmbH})$, Ingolstädter Landstrasse 1, D-85764 Neuherberg, Germany. The authors want to thank to Tetrahymena Stock Center, C5 155 Veterinary Medical Center, Cornell University, Ithaca, New York 14853 322 for providing Tetrahymena thermophila cell line. In addition, there is no known conflict of interest associated with this publication.

\section{References}

1. Bermudez E, Mangum JB, Wong BA, Asgharian B, Hext PM, et al. (2004)
Pulmonary responses of mice, rats, and hamsters to subchronic inhalation of ultrafine titanium dioxide particles. Toxicol Sci 77: 347-357.

2. Chen HW, Su SF, Chien CT, Lin WH, Yu SL, et al. (2006) Titanium dioxide nanoparticles induce emphysema-like lung injury in mice. FASEB J 20: 23932395.

3. Dai K, Peng T, Ke D, Wie B (2009) Photocatalytic hydrogen generation using a nanocomposite of multi-walled carbon nanotubes and $\mathrm{TiO} 2$ nanoparticles under visible light irradiation. Nanotech 20: 125603.

4. Soto K, Garza KM, Murr LE (2007) Cytotoxic effects of aggregated nanomaterials. Acta Biomater 3: 351-358.

5. Warheit DB, Webb TR, Reed KL, Frerichs S, Sayes CM (2007) Pulmonary toxicity study in rats with three forms of ultrafine-TiO2 particles: differential responses related to surface properties. Toxicology 230: 90-104.

6. IvankoviÄ $\ddagger$ S, Musiä $\ddagger$ S, GotiÄ $\ddagger$ M, LjubesiÄ $\ddagger$ (2006) Cytotoxicity of nanosize $\mathrm{V}(2) \mathrm{O}(5)$ particles to selected fibroblast and tumor cells. Toxicol In Vitro 20 : 286-294.

7. Dai Y, Xiao H, Liu J, Yuan Q, Ma P, et al. (2013) In Vivo Multimodality Imaging and Cancer Therapy by Near-Infrared Light-Triggered trans-Platinum Pro-DrugConjugated Upconverison Nanoparticles. J Am Chem Soc 135: 18920-18929.

8. Xu H, Cheng L, Wang C, Ma X, Li Y, et al (2011) Bottom of Form Polymer encapsulated upconversion nanoparticle/iron oxide nanocomposites for multimodal imaging and magnetic targeted drug delivery. Biomaterials 32 9364-9373.

9. Ma P, Xiao H, Li X, Li C, Dai Y, et al. (2013) Rational design of multifunctional upconversion nanocrystals/polymer nanocomposites for cisplatin (IV) delivery and biomedical imaging. Adv Mater 25: 4898-4905

10. Mercer RR, Hubbs AF, Scabilloni JF, Wang L, Battelli LA, et al. (2010) Distribution and persistence of pleural penetrations by multi-walled carbon nanotubes. Part Fibre Toxicol 7: 28.

11. Tin-Tin-Win-Shwe, Mitsushima D, Yamamoto S, Fukushima A, Funabashi T, et al. (2008) Changes in neurotransmitter levels and proinflammatory cytokine 
Citation: Ud-Daula A, Schramm K (2015) Nanoparticulat Printex 90 and Titanium Dioxide Stimulate Catecholamine Production in Ciliated Protozoan, Tetrahymena thermophila. Biochem Anal Biochem 4: 212. doi:10.4172/2161-1009.1000212

Page 5 of 5

mRNA expressions in the mice olfactory bulb following nanoparticle exposure. Toxicol Appl Pharmacol 226: 192-198

12. Lam CW, James JT, McCluskey R, Hunter RL (2004) Pulmonary toxicity of single-wall carbon nanotubes in mice 7 and 90 days after intratracheal instillation. Toxicol Sci 77: 126-134.

13. Warheit DB, Laurence BR, Reed KL, Roach DH, Reynolds GA, et al. (2004) Comparative pulmonary toxicity assessment of single-wall carbon nanotubes in rats. Toxicol Sci 77: 117-125.

14. Shvedova AA, Castranova V, Kisin ER, Schwegler-Berry D, Murray AR, et al. (2003) Exposure to carbon nanotubes material: assessment of nanotubes cytotoxicity using human keratinocyte cells. J Toxicol Environ Health 66: 1909-1926.

15. Afaq F, Abidi P, Matin R, Rahman Q (1998) Cytotoxicity, pro-oxidant effects and antioxidant depletion in rat lung alveolar macrophages exposed to ultrafine titanium dioxide. J Appl Toxicol 18: 307-312.

16. Shimizu M, Tainaka H, Oba T, Mizuo K, Umezawa M, et al. (2009) Maternal exposure to nanoparticulate titanium dioxide during the prenatal period alters gene expression related to brain development in the mouse. Part Fibre Toxicol 6: 20.

17. Wang J, Chen C, Liu Y, Jiao F, Li W, et al. (2008) Potential neurological lesion after nasal instillation of $\mathrm{TiO}(2)$ nanoparticles in the anatase and rutile crystal phases. Toxicol Lett 183: 72-80.

18. Mortimer M, Kasemets K, Vodovnik M, Marinšek-Logar R, Kahru A (2011) Exposure to $\mathrm{CuO}$ Nanoparticles Changes the Fatty Acid Composition of Protozoa Tetrahymena thermophila. Environ Sci Technol 45: 6617-6624.
19. Mortimer M, Kasemets K, Kahru A (2010) Toxicity of ZnO and CuO nanoparticles to ciliated protozoa Tetrahymena thermophila. Toxicology 269: 182-189.

20. Shi JP, Ma CY, Xu B, Zhang HW, Yu CP (2012) Effect of light on toxicity of nanosilver to Tetrahymena pyriformis. Environ Toxicol Chem 31: 1630-1638.

21. Juganson K, Mortimer M, Ivask A, Kasemets K, Kahru A (2013) Extracellular conversion of silver ions into silver nanoparticles by protozoan Tetrahymena thermophila. Environ Sci Process Impacts 15: 244-250.

22. Ud-Daula A, Pfister G, Schramm KW (2008) Growth inhibition and biodegradation of catecholamines in the ciliated protozoan Tetrahymena pyriformis. J Environ Sci Health A Tox Hazard Subst Environ Eng 43: 16101617.

23. Ud-Daula A, Pfister G, Schramm KW (2013) Method for toxicity test of titanium dioxide nanoparticles in ciliate protozoan Tetrahymena. J Environ Sci Health A Tox Hazard Subst Environ Eng 48: 1343-1348.

24. Takahashi F, Mizuo K, Shinkai Y, Oshio S, Takeda K (2010) Prenatal exposure to titanium dioxide nanoparticles increases dopamine levels in the prefronta cortex and neostriatum of mice. J Toxico Sci 35: 749-756

25. Jacobsen NR, White PA, Gingerich J, Møller P, Saber AT, et al. (2011) Mutation spectrum in FE1-MUTA(TM) Mouse lung epithelial cells exposed to nanoparticulate carbon black. Environ Mol Mutagen 52: 331-337.

26. Tsunoda M (2006) Recent advances in methods for the analysis of catecholamines and their metabolites. Anal Bioanal Chem 386: 506-514. 